\title{
Transgenerational Effects of PTSD or Traumatic Stress: Do Telomeres Reach Across the Generations?
}

\author{
Küffer $A^{1,3 *}$, Maercker $A^{1,3}$ and Burri $A^{2}$
}

${ }^{1}$ Department of Psychology, Division of Psychopathology and Clinical Intervention, University of Zurich, Switzerland

${ }^{2}$ Department of Psychology, Division of Clinical Psychology for Children/Adolescents and Couples/Families, University of Zurich, Switzerland

${ }^{3}$ University Research Priority Program "Dynamics of Healthy Aging”, Switzerland

\begin{abstract}
Traumatic stress can alter allostatis and therefore mediate the development of psychological disorders. Recent evidence from molecular studies has shown that telomere length - a measure of cellular aging - is strongly influenced by a broad spectrum of stress. Telomere erosion might be accelerated by traumatic stress, and traumatic stress has shown to be associated with the risk of developing chronic diseases like cancer, cardiovascular diseases and immunologic conditions. Aim: The biological pathways between psychological stress and psychological disorders or physiological diseases are widely unknown. Some experimental studies in animal models and longitudinal studies in humans have investigated the transgenerational consequences of psychological stress on telomere length biology. Telomere length inheritance might provide an additional molecular mechanism for the germ line transmission of environmentally induced phenotypic change and might offer a new biological framework for the multifactorial path etiology underlying stress-related disorders. Procedure: Starting from the well-established allostatic load model, this article reviews theoretical and empirical work from animal models and humans in the field of telomere biology in association with traumatic stress, childhood trauma and post-traumatic stress disorders. Further it reviews recent approaches on telomere length inheritance, and combines these findings with transgenerational research of post-traumatic stress disorder biology. Conclusion: A better understanding of the transgenerational mechanisms underlying common diseases might ultimately help disease prevention of stress related disorders in subsequent generations.
\end{abstract}

Keywords: Telomere length; Allostasis; Transgenerational; Stress; Trauma; Post-traumatic stress disorder; PTSD

\section{Introduction}

In the last few decades, research has focused strongly on identifying biomarkers that are associated with stress- and trauma-related disorders. This research provided the empirical evidence for several etiological models that explain the pathways from physiological symptoms to psychological disorders and vice versa. One of the best-known is McEwen and Stellar's allostatic load (AL) model, which describes the multidimensional effects of physiological and psychological stress [1$3]$. In the AL model, an organism's need to meet its external demands (i.e., environmental influences perceived as stress) is termed allostasis.

This short review discusses the possibility of transgenerational inheritance of stress- and trauma-related telomere length (TL) shortening as a molecular outcome according to the AL model. Unlike previous reviews on TL and stress [4-6], we aim to integrate the idea of transgenerational aspects in TL biology in relation to stress exposure from animal models and from studies with human participants. We will first provide an introduction to telomere biology (i.e. the function of telomeres, their erosion processes, and their tissue stability) and then summarize recent research efforts that may introduce TL as a marker for stress-related disorders. This article will have a special focus on studies investigating Post-Traumatic Stress Disorder (PTSD) and childhood adversities and/or trauma, representing both models for conditions specifically associated with elevated amount of lifetime stress. Finally we will present a number of findings from transgenerational telomere biology and associate it to stress-related research (including traumatic stress) to present a new hypothesis in the field of psycho-biological research: TL shortening is not only a primary result of psychological stress, but also possibly a biological mediator for stress inheritance to subsequent generations. Overall, this short review addresses a new aspect of the biological framework and etiology of stress-related disorders and explores implications for the prevention.

\section{Chronic Stress and Allostasis}

Allostasis represents the sum of chronic exposure to heightened fluctuating or repeated environmental challenges and therefore offers a biological paradigm for the effects of stress on an organism's psychobiologic well-functioning. The model describes three levels of outcome [1]. The primary effects refer to a molecular level, in which cellular activities (e.g., gene-expression, receptors, enzymes, etc.) are affected. The second outcome level defines sub-clinical levels of physiological parameters (e.g. insulin, glucose, cholesterol, systolic and diastolic blood pressure, etc.), eventually leading to a range of stress-related diseases. The last outcome level represents the final stage of physiological deregulations and diseases [7]. According to the model, even small deregulations to molecular levels may lead to disadvantageous consequences in the long term [7]. Within the AL model, molecular biomarkers are classified as primary effects, and play a fundamental role given that they appear early in the development of psychopathology. As such, the identification of relevant biomarkers

*Corresponding author: Andreas Kuffer, Divison of Psychopathology and Clinical Intervention, University of Zurich, Switzerland, Fax: +41 4463573 19; Tel: +41 44 63573 03; E-mail: a.kueffer@psychologie.uzh.ch

Received June 26, 2014; Accepted July 26, 2014; Published July 28, 2014

Citation: Küffer A, Maercker A, Burri A (2014) Transgenerational Effects of PTSD or Traumatic Stress: Do Telomeres Reach Across the Generations? J Trauma Treat 3: 204. doi:10.4172/2167-1222.1000204

Copyright: (C) 2014 Küffer A, et al . This is an open-access article distributed under the terms of the Creative Commons Attribution License, which permits unrestricted use, distribution, and reproduction in any medium, provided the original author and source are credited. 
of stress is particularly important to elucidate the interplay between nature and nurture of stress-related disorders.

To date, many molecular markers have already been investigated with the spectrum reaching from genetic variations like Single Nucleotide Polymorphisms (SNPs) and Copy Number Variations (CNVs), to epigenetic variations like CpG-rich or -poor regions with distinctive DNA methylation patterns [8]. Telomere length (TL) represents another such candidate for molecular variation that seems to be especially prone to environmental influences. A number of working groups have confirmed the association between psychological stress and TL-shortening [9-13]. In brief, the findings suggest that the more an individual is exposed to chronic stress, the shorter the individual's telomeres are.

\section{Structure and Function of Telomeres}

Telomeres were first described in the Journal of Molecular Biology by Elisabeth Blackburn and Joseph Gall in 1978 [14]. They are the protective caps located at the ends of the 23 human chromosome pairs and at the ends of other eukaryotic chromosomes, made of repeats of specific nucleotide sequences organized in tandem arrays. In humans the telomeric sequence is 5'-TTAGGG-3'. The number of repeats varies greatly between species and between and within subjects (see below). Telomeres are involved in maintaining genomic stability and regulating cellular proliferation [15]. They have been shown to inhibit chromosomes to form end-to-end fusions by preventing the cell from identifying telomeres as DNA-double strand breaks $[15,16]$.

TL has a strong genetic basis with heritability estimates ranging from $34 \%$ to $82 \%[17,18]$. A meta-analysis looking at six populations including over 19 '700 subjects aged 17 to 99 years found a mean heritability rate of $70 \%$ [19]. Findings from quantitative trait linkage studies further identified several putative loci for TL in several genes, such as the telomerase RNA component (TERC), the Telomerase Reverse Transcriptase (TERT), the nuclear assembly factor 1 ribonucleoprotein (NAF1), oligonucleotide/oligosaccharide-binding fold containing 1 (OBFC1) or the regulator of telomere elongation helicase 1 (RTEL1) [20-23].

\section{Telomere Shortening and Erosion}

In somatic cells telomeres progressively shorten with each mitotic division because of the inability of DNA polymerase to fully replicate the 3 '-end of the DNA strand. In other words, with each cell replication cycle a small fragment of DNA cannot be replicated due to the nature of the replication process itself. This inability of copying the last nucleic acids results in a loss of about 50 basepairs of telomere sequences per cell doubling. This process is known as the end-replication problem, which is partly held responsible for biological aging [24-26]. In order to prevent chromosomes from losing essential genetic information, telomeres close up the chromosomal DNA strands described above. Instead of shortening a gene, the chromosome only loses some of its TL. Thus, telomeres act as the mitotic clocks of our body, allowing a mitotic cell only to replicate itself for a certain number of times until its telomeres shorten down to a critical length and therefore lead to cellular senescence [27]. This was elegantly illustrated in a longitudinal study conducted on transgenic mice, where the rate of increase in the percentage of short telomeres was predictive of the mice' life expectancy [28], and where telomerase-deficient cells (see below) with single short telomeres caused an earlier onset of senescence [29].

With a specific enzyme our body can compensate for some of this $\mathrm{TL}$ erosion. Telomerase is aribonuclearprotein which counteracts
TL shortening by a specialized reverse transcriptase adding the 5'-TTAGGG-3'oligonucleotides to the 3'-end of the DNA-strand $[30,31]$. Telomerase is not active in all mitotic cells and is particularly important in cells that depend on replication of vast numbers (e.g. sperm cells, stem cells or activated lymphocytes). It is also believed to play an important role in immortalizing tumor cells by allowing them to intently proliferate without substantial TL loss. Except in sperm cells and tumors - where telomerase can elongate telomeres - telomerase can only slow down TL erosion without preventing it completely $[32,33]$.

TL erosion due to proliferation of mitotic cells is one important, though most probably not the only mechanism causing shortened TL. DNA-strand damages are another reason held responsible for TL erosion [34]. Apart from other exogenous sources that may damage molecular structures (e.g. UV-light, radiation, ozone etc.) telomeres have also been found to be affected by oxidative stress. It occurs when the enzymatic and non-enzymatic antioxidants fail to fully neutralize reactive oxygen species (ROS) [35]. ROS are chemically instable molecules (e.g. superoxide, hydrogen peroxide, hydroxyl radical, nitric oxide), which are highly reactive to their cellular environment and tend to damage DNA by binding to nearby molecules $[36,37]$. Monaghan et al. [35] describe the effects of oxidative stress as a homeostasis between ROS and antioxidants [35]. Oxidative stress occurs when the balance between the two agents shifts in favor of ROS. Hence, while ROS are responsible for the damage on the DNA, information about both agents are necessary in order to comprehend the picture (Monaghan et al.[35] povide further details on the interaction between ROS and antixidants). Oxidative stress is particularly important as a damaging mechanism because psychological stress has been shown to reduce antioxidative activity and to increase indices of ROS [38].

Beside these mechanisms - cellular turnover and DNA-strand damages due to ROS - other key players might contribute to TL shortening. Inflammation has been associated with TL loss, though pathways are not yet fully understood. One plausible hypothesis is that inflammation increases by moderating the metabolic demands. Hence, inflammation may increase cellular turnover and metabolism, leading to more ROS due to more mitochondrial activity for example. Studies have repeatedly shown an association between inflammation markers and progressed TL erosion, indicating the involvement of inflammation in TL erosion [39]. Another plausible hypothesis is that the immune activation itself leads to shorter TL by the rapid recruitment and differentiation of younger immune cells. Figure 1 summarizes the described pathway between psychological stress and TL erosion.

It is important to note that it is not inflammation per se seems to shorten TL, but more likely the cellular renewal and increased metabolism, which most likely is induced by inflammation, is held responsible for the shortening. Further note that these two hypotheses are neither mutually exclusive, nor the only plausible mechanisms for TL erosion. They rather represent two complementary mechanisms to explain the implication of inflammation in TL erosion.

\section{Telomeres in Different Tissues}

Stability between TL in different healthy tissue samples and over time is not yet clearly determined and remains an area of active research. So far, only few studies have compared TL concordance across different tissues [40-45], and to date no study observed TL dynamics in different tissue samples across multiple time points to compare TL dynamics between tissues over time. Still, some cross-sectional studies report synchrony over different tissues. One study by Kimura et al. [40], for example, 


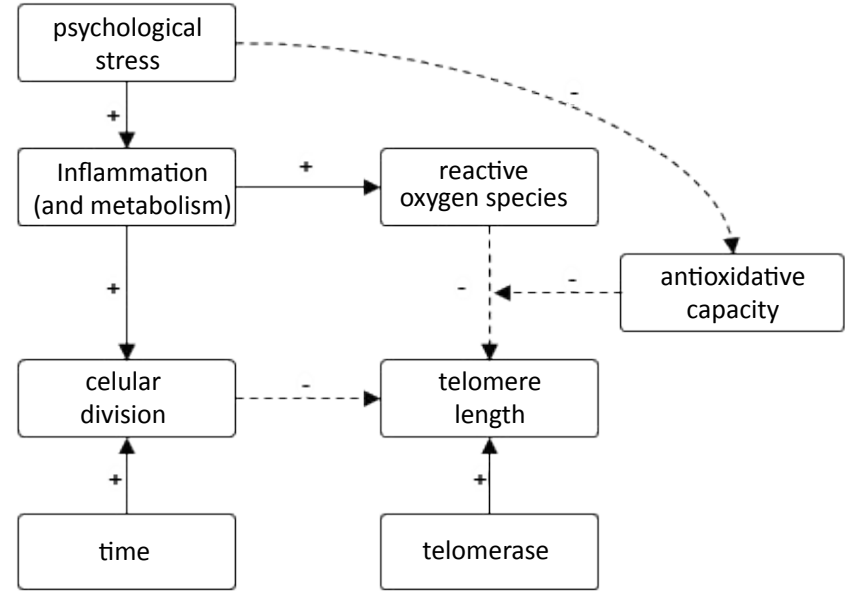

Figure 1: Pathways between stress and telomere erosion are currently still an active field of research. Plausible influence leads over oxidative stress and inflammation. Inflammation my increase cellular turnover and produce more reactive oxygen species, because of more metabolism. Antioxidative capacities neutralize ROS, while psychological stress decreases antioxidative capacities. Arrows indicate correlations, while minus signs on dashed arrows indicate negative correlation and plus signs on solid arrows indicate positive correlations.

reported significant correlations between TL of hematopoietic progenitor cells from newborn umbilical cord blood samples and TL from lymphocytes or granulocytes, with $\mathrm{r}$ 's ranging from $r=.88$ to $r$ $=.94$ [40]. In a second phase of their study, they showed that correlation between granulocytes TL and leukocyte TL were high at birth $(r=.98)$ and stayed strong different age groups $(r=.98)$. These results derived from cross-sectional data of a cohort with 24 subjects (age 22 to 34 years) and another cohort with 400 subjects (age 0 to 100 years) [40]. Some studies implied TL synchrony between different tissue samples across different stages of an organism's development. A comparison of tissue samples from 13 different organs in 11 aborted fetuses (gestations weeks 15-19), for example, found no significant differences of mean $\mathrm{TL}$ across the tissues, with mean ranges being less than 1 kilobase for all samples [41]. Similarly, another study conducted on newborns found a strong correlation $(r=.89)$ between TL of white blood cells and TL of umbilical artery cells [43]. And in two post-mortem samples of 41 and 21 subjects from 0 to 101 years of age, Nakamura reported significant associations in lingual epithelium cell TL and epidermis TL ( $r=.84$ and $r=.93$, respectively) [42]. By additionally controlling for donor age, Friedrich and colleagues found significant correlations in tissue samples from 9 patients (age 75-95 years) between epidermis TL and leukocyte TL $(\mathrm{R} 2=.79)$, epidermis TL and synovial sample TL $\left(R^{2}=.71\right)$, and synovial sample TL and leukocyte TL $\left(R^{2}=.54\right)[45]$. Whilst these studies point towards TL tissue synchrony, one study failed to find evidence for such synchrony. Thomas, O'Callaghan, and Fenech found no significant correlation between buccal cell TL and whole blood cell TL in three different samples, including 30 young adults (age 18-26 years), 26 healthy old adults (age 64-74 years) and 54 clinically diagnosed Alzheimer's patients (age 58-93 years) respectively [45]. While there are several indications that there is a substantial correlation between TL in different tissues, it is important to note that most studies on the subject of tissue-correlation incorporated only small sample sizes. Combined with the small number of studies in this particular field, satisfying conclusions cannot yet be drawn on how strong synchrony is over different tissue samples.

\section{Stress Related Disorders over Subsequent Generations and TL}

\section{The Effects of Stress, Traumatic Stress and PTSD on TL}

Telomeres are not only considered an index of cellular age but have also been associated with physical morbidity and mortality. Associations between shorter TL and a number of disorders have been reported, such as cancer [46,47], immune [48], and cardiovascular diseases [49,50]. Besides these physical disorders, psychological conditions (i.e. psychological stress) have become more important in research over time.

A recent experiment using an animal model demonstrated the impact of early post-natal life stress and subsequent TL erosion in erythrocytes [51]. The authors divided a total of 114 European shag chicks in three groups: an unhandled control group of 36 chicks, a handled-CORT group of 42 chicks and a handled-oil group of 36 chicks. The CORT-group received oral administered corticosterone to elevate glucocorticoid hormone levels, while the handled-oil group received fish oil to induce a comparable amount of exogenous stress levels. The chick's erythrocytes TL were measured 10 days after hatching and 20 days later after subsequent stress manipulation. Though there was no significant difference between the two stress groups, both groups showed significant shorter telomeres compared to the control group.

Recent studies in humans, although all non-experimental, suggest that stress has a similar impact on human TL biology. Epel and colleagues demonstrated a significant association between lifetime stress and shortened telomeres. Within the last decade, researchers have highlighted further facets of stress [9]. A considerable number of studies found significant relationships between stress, traumatic stress (and its consequences, such as PTSD) and TL, including experimental confirmation in animal models [51,52], and a series of studies demonstrating this in children as well as adults exposed to early adversity. The following paragraph provides a summary of these findings.

In a prospective longitudinal study with two measurement points conducted on 236 children at the age of 5 and 10 years, Shalev and colleagues showed that children with more exposure to violence also had significantly more TL erosion (i.e. shorter TL at age of 10 compared to the age of 5 years) compared to children with less exposure to violence [53]. Using a prospective design including repeated measurements, this study provided evidence that childhood stress might have impaired telomere maintenance in the long run. According to the authors, TL erosion might have been a direct consequence of chronic childhood stress rather than the product of moderating/mediating variables (such as poor physical health in adulthood due to childhood maltreatment). In other words, telomere erosion does not seem to be the cause of later health problems, but a proximal effect of maltreatment itself. Also in 2012, Drury published their study on the association between foster care placement and TL. The authors considered children living in institutions as a model for early adversities [54]. They investigated a total of 136 children allocated to one of six institutions in Bucharest (Romania). For TL baseline assessment, buccal swaps were collected between 6 and 30 months of age, and compared with TL from 54 months of age. The percentage of time spent in institutional care was used to predict TL. Percent time spent in the institution was significantly and negatively associated with TL and remained so, even after controlling for potential cofounders like gender, ethnicity, low birth weight and age at telomere collection. Recently, Drury and colleagues published a cross-sectional study about 80 (age 5-15 years) children who were 
exposed to family violence and disruptions. After controlling for age, sex, maternal education (as a proxy for socio economic status), and paternal age of conception (PAC), they found that the number of adverse life events were significantly associated with TL [55]. Children with no exposure to adverse family events had significantly longer TL than those exposed to one, two or more events. Savolainen aimed to replicate the findings of Drury et al. [55] in a sample of 1486 old adults (mean of 61.5 years age at the time of tissue collection), where 215 had been separated from their parents in childhood [56]. Additionally to the parental separation, they assessed self-reported physically and emotionally traumatic experiences throughout the lifespan with the Traumatic Experiences Checklist (TEC). Even though they did not find a significant association between LTL and the early life separation, emotional or physical trauma over the total sample, the group found shorter TL in the participants who were separated from their parents in childhood and reported traumatic experiences in their lifespan. In line with this model, a study conducted by O'Donovan et al. [48] on 43 patients with chronic PTSD and 47 control subjects found significant associations between PTSD diagnosis and TL shortening [47]. In the same study, a significant association between childhood trauma (CT) and telomere shortening was found within the PTSD group. Additionally, exposure to cumulative CT was linearly associated with shorter TL. CT was assessed dichotomously by the participants' perception of life threat after experiencing physical neglect, family violence, physical abuse, forced sexual touch, or forced sexual intercourse before the age of 14 years. In a relatively large sample of 4441 women (aged 41-80 years) from the United Kingdom mean TL was significantly associated with adverse experiences during childhood, also after controlling for various covariates (e.g. social class, obesity, smoking status, preexisting disease, physical health, and self-reported health) [57]. In this study the number of adverse events until an age of 17 years reported by the participants predicted whole blood TL negatively. Similar findings were reported by Kananen et al. [10], who investigated 321 individuals with anxiety disorder and matched controls (age 30-87 years) [10]. They found that the total cumulative number of childhood adversities was significantly associated with TL by the means of a linear relationship: the more adversities subjects reported, the shorter their telomeres were. Providing further support to these childhood adversities-TL erosion findings, childhood maltreatment was significantly associated with TL in a sample of 31 adults [13]. Tyrka and colleagues administered the childhood trauma questionnaire (CTQ) to subjects with no current mental disorder to check associations between CTQ and TL. According to their CTQ scores, participants were allocated to a no-maltreatment group when they reported no maltreatment or only moderate scores in the five CTQ subscales "physical abuse", "sexual abuse", "emotional abuse", "physical neglect" and "emotional neglect". Participants with moderate to severe scores were selected for the maltreatment group accordingly. Like the other authors, Tyrka et al. [13] found shorter TL within the participants with childhood maltreatment (e.g. the maltreatment group).

It is not only adverse childhood experiences that seem to be significantly associated with TL. In a seminal study conducted on a sample of 3000 subjects, PTSD was significantly associated with shorter TL [58]. PTSD was assessed with the Posttraumatic Diagnostic Scale and the Impact of Event Scale, and participants were assigned to three different groups. Depending on their PTSD status, participants were assigned to three different groups (i.e., no PTSD, partial PTSD, and full PTSD). Even though significant differences could only be detected between the no PTSD group and the two other groups (but not between the partial PTSD, and full PTSD group), the findings point towards a linear association in terms of a dose-response model: the stronger the PTSD symptomatology, the shorter the mean TL. Finally, a longitudinal study investigating the sequelae of rape in 64 females with PTSD, where of 23 were also diagnosed with major depressive disorder (MDD), the authors provided further support to the association between TL and PTSD (albeit not between TL and MDD) [12]. In an investigation conducted on 650 volunteering US army special operation units (with exposure to combat experiences), [59] found lower LTL in participants who scored positive for PTSD, compared with those who scored negative for PTSD. In 2014, Shalev et al. [60] conducted an analyses in a subsample of 827 participants from the Dunedin Study (N=1037 original birth cohort), where leukocyte TL and psychometric data was available [60]. Their results showed that the persistence of internalizing disorders (i.e. depression, generalized anxiety disorder and PTSD) among men predicted shorter leukocyte $\mathrm{TL}$ at age 38 in a dose-response manner. Where leukocyte TL data was available at age 26 and later at age 38 , they were able to predict TL erosion over the given time. Male participants who developed one of the previous described disorders over the course of the 12 years, showed significantly stronger decline in TL than there healthy controls. In order to explain the given sex difference in their study, the authors cited consistent findings which found that men with mental disorders, are at higher risk for mortality than females with mental disorders and that physiological and biochemical systems, which are associated with higher oxidative stress and inflammatory markers, might be more affected in men with mental disorders. Further they hypothesized that the sex difference might be due to the fact, that the study period covered the women's reproductive phase, which might act as a protective factor for TL erosion. Estrogen is thought to have mitochondrial anti oxidative properties. Further, telomerase expression and activity is increased in the presence of estrogens. Therefore, the authors suggest, women might be less susceptible to disorder-linked telomere erosion during their reproductive phase.

Overall, these study results suggest that shortened TL might be the biological consequences of stress exposure during lifetime. Together with other risk factors (see below) TL might represent a plausible biomarker for PTSD and disorders specifically associated with stress. Nevertheless, it remains unclear how adverse life events affect TL biology and further studies are needed to elucidate the mechanisms of this trauma-TL association.

\section{Intergenerational Transference of Stress-induced Psychopathologies}

It is well established that environmental exposures such as stress, trauma or exposure to toxins during fetal and early postnatal development can lead to an increased incidence of adult-onset diseases [61-64]. However, the mediating biological mechanisms from environmental stressors to individual disorders remain unclear. A recent study on mice demonstrated a potential mechanism which might contribute to gene-environment interactions [65]. The authors suggested that small non-coding (snc) RNAs might play a causal role in transgenerational inheritance of traumatic experience by injecting purified sperm sncRNAs from traumatized mice (by a model of unpredictable maternal separation and unpredictable maternal stress; MSUS) into wild-type fertilized mouse oocytes. RNA injected mice showed significantly altered response to aversive conditions and even depressive-like symptoms. At the same time the authors investigated the glucose metabolism in the MSUS (F1) mice mentioned above, non-traumatized control mice (F1 controls), and the offspring of both groups (F2). Through glucose and insulin tolerance tests the authors 
suggested that the F2 MSUS mice showed insulin hypersensitivity and over all a hyper metabolism. These findings are in line with the in Figure 1 suggested pathways of TL erosion, since metabolism, indirectly induced through psychological stress, might lead to shorter TL. To our knowledge, there are no studies, which investigated those mechanisms in humans so far. But a limited number of studies have focused on transgenerational consequences of perceived parental stress and telomere biology.

In 2011, Entringer et al. [66] investigated the association between leukocyte TL in a sample of 94 healthy subjects and their exposure to intrauterine stress (i.e., prenatal stress) [66]. Their parental stress exposure was a significant predictor for TL length, even after controlling for important potential confounders such as birth weight, early-life stress and current stress. In 2013, the same group conducted a study on 27 mother-newborn dyads in order to assess how early maternal stress levels during pregnancy (i.e. also prenatal) affect newborn leukocyte TL [67]. In this second study, the authors found further evidence for significantly shorter leukocyte TL in newborns from mothers with greater stress exposure, indicating some sort of stress-related programming reflected in newborn TL. The authors discussed that stress-induced release of maternal hormones may lead to inflammation and oxidative stress mediation.

As suggested by Gapp and colleges [65], the male germ line might provide particular insights in the mechanisms of biological traumatransmission. Allsopp et al. [68] for example, reported that sperm telomeres in human - maintained by telomerase - increase 71 base pairs in length per year [68]. That implies that paternal TL deserves further emphasis. While female germ cells develop and proliferate during the second trimester of gestation and afterwards rest in post mitotic stage [69], spermatogenesis in testis starts after puberty and continues until death, and therefore-unlike oocytes - sperm cells rest mitotic and proliferating. Sperm cells would enter senescence very early if it were not for telomerase. Telomerase counterbalances the TL loss over time in healthy mitotic cells, such as sperm cells, leading to a constant sperm TL over time or even a slightly elongated sperm TL.
Previous studies have suggested that sperm TL of older men are longer than those of younger men [68,70]. Given the correlation between sperm TL and paternal age, it seems evident that PAC or paternal age of birth (PAB) could serve as a proxy for the assessment of TL inheritance in subsequent generations. Several research groups have already used this procedure. Table 1 provides a brief overview of studies conducted on samples in which $\mathrm{PAC} / \mathrm{PAB}$ was associated with offspring TL.

Broer [19] and colleagues investigated not only TL heritability but also TL inheritance by investigating the correlation between offspring TL and parental TL. They checked for paternal and maternal effects separately and found a strong association with both parents (mother-offspring correlation of $r=.42$; father-offspring-correlation of $r=.33$ ) [19]. Interestingly, the meta-analysis also indicated a positive association between $\mathrm{PAB}$ and offspring TL across five different samples (Table 1). The older the fathers were at the birth of their children, the longer the children's mean TL was. Several other research groups reported similar findings. In a study conducted on a sample of 2433 subjects (1176 men and 1257 woman) with an age-range of 35 to 55 years, $\mathrm{PAB}$ was positively associated with offspring TL [71]. In a study from 2005, Unryn et al. [72] investigated 125 randomly chosen subjects (51 men and 74 women), and also found a strong association between PAC and offspring TL $(r=.46)$ [72]. Njajou and colleagues reported heritability estimates of $44 \%$ [17]. Consistent with the findings of the other research groups, they also observed a significant positive association between paternal TL and offspring TL and a significant PAC-offspring TL association in a subsample, and therefore for TL inheritance. Kimura [73] observed a significant association between $\mathrm{PAB}$ and offspring TL in four different cohorts (resulting in a total of 3365 subjects. This was supported by findings from Arbeev et al. and Eisenberg et al. [74,75].

\section{TL and its Association with Transgenerational PTSD Susceptibility}

Most research on transgenerational aspects of stress has focused on

\begin{tabular}{|c|c|c|c|c|c|c|}
\hline References & Samples & $\mathbf{N}$ & $\begin{array}{c}\text { Age } \\
m(s d) / r a n g e\end{array}$ & PAC/PAB & $\begin{array}{l}\text { Effect } \\
(r / \beta)\end{array}$ & $p$ \\
\hline \multirow{5}{*}{ Broer et al. (2013) } & Erasmus Rucphen Family & 560 & $26.7(4.1)$ & $\mathrm{PAB}$ & $\beta(T L / y)=0.0086 \pm 0.0038$ & 0.024 \\
\hline & GRAPHIC Study & 983 & $28.3(4.2)$ & $\mathrm{PAB}$ & $\beta(T L / y)=0.0053 \pm 0.003$ & 0.077 \\
\hline & Leiden Longevity Study & 1587 & $35.5(5.9)$ & PAB & $\beta(T L / y)=0.0029 \pm 0.0021$ & 0.167 \\
\hline & The Netherlands Twin Register & 1305 & $30.0(4.6)$ & PAB & $\beta(T L / y)=0.0080 \pm 0.0031$ & 0.01 \\
\hline & Queensland Institute of Medical Research & 869 & $32.2(5.3)$ & $\mathrm{PAB}$ & $\beta(T L / y)=0.0066 \pm 0.0048$ & 0.0013 \\
\hline \multirow{2}{*}{$\begin{array}{l}\text { Eisenberg, Hayes and } \\
\text { Kuzawa (2012) }\end{array}$} & Cebu sample (offspring) & 1681 & $36-69-y$ & PAB & $\beta(T L / y)=0.0027 \pm 0.0013$ & $>0.0001$ \\
\hline & Cebu sample (grand children) & 234 & $21-23 y$ & GPAB & $\beta(T L / y)=0.0029 \pm 0.0027$ & 0.038 \\
\hline $\begin{array}{l}\text { Arbeev, Hunt, Kimura, Aviv } \\
\text { and Yashin (2011) }\end{array}$ & Family Heart Study & $\begin{array}{c}2177 \\
(995 \mathrm{~m} / 1182 \mathrm{w})\end{array}$ & $31-86$ y & $\mathrm{PAB}$ & $\begin{array}{l}\mathrm{m}: \beta(b p / y)=12.9 \pm 9.6 \\
w: \beta(b p / y)=19.4 \pm 10.1\end{array}$ & $\begin{array}{l}0.012 \\
0.002\end{array}$ \\
\hline \multirow{4}{*}{ Kimura et al. (2008) } & Framingham Heart Study & $\begin{array}{c}432 \\
(235 \mathrm{~m} / 197 \mathrm{w})\end{array}$ & $18-80$ y & PAB & $\begin{array}{c}m: r=0.21 \\
w:-\end{array}$ & $\begin{array}{c}=0.001 \\
\mathrm{~ns}\end{array}$ \\
\hline & Family Heart Study & $\begin{array}{c}847 \\
(355 \mathrm{~m} / 492 \mathrm{w})\end{array}$ & $32-84$ y & PAB & $\begin{array}{l}\mathrm{m}: \mathrm{r}=0.19 \\
\mathrm{w}: \mathrm{r}=0.14\end{array}$ & $\begin{array}{l}0.0003 \\
0.016\end{array}$ \\
\hline & Longitudinal Study of Aging Danish Twins & $\begin{array}{c}132 \\
(44 \mathrm{~m} / 88 \mathrm{w})\end{array}$ & $73-94$ y & PAB & $\begin{array}{c}m: r=0.63 \\
\quad w:-\end{array}$ & $\begin{array}{l}0.001 \\
\mathrm{~ns}\end{array}$ \\
\hline & UK adult twin registry & 1954 w & $18-79 y$ & PAB & $w: r=0.17$ & 0.001 \\
\hline De Meyer et al. (2007) & Asklepios study population & $\begin{array}{c}2433 \\
(1176 \mathrm{~m} / 1257 \mathrm{w})\end{array}$ & $35-55$ y & PAB & $\begin{array}{l}\mathrm{m}: \beta(\mathrm{bp} / \mathrm{y})=15.5 \pm 5.9 \\
\mathrm{w}: \beta(\mathrm{bp} / \mathrm{y})=19.1 \pm 6.1\end{array}$ & $\begin{array}{l}>0.0001 \\
>0.0001\end{array}$ \\
\hline Njajou et al. (2007) & Amish families & $\begin{array}{c}229 \\
(89 \mathrm{~m} / 140 \mathrm{w})\end{array}$ & $18-92$ y & PAC & $\beta(b p / y)=10.4 \pm 8.44$ & 0.05 \\
\hline Unryn et al. (2007) & Random subjects & $\begin{array}{c}125 \\
(51 \mathrm{~m} / 74 \mathrm{w})\end{array}$ & $30-80 y$ & PAC & $r=0.46$ & 0.01 \\
\hline
\end{tabular}

$\mathrm{PAC}=$ parental age of conception; $\mathrm{PAB}=$ parental age of birth GPAB = grandparental age of birth; TL/y = telomere length per years; bp/y = base pairs per years; $m=$ men; $w=$ women.

Table 1: Overview of different studies that have investigated the effect of parental age of conception or birth on TL. 
individuals suffering from PTSD. Familial accumulation of PTSD has led researchers to the conclusion that PTSD has a genetic component [76-78]. In other words, parental PTSD appears to be a salient risk factor for the susceptibility to develop a PTSD in subsequent generations. In a seminal study conducted on Holocaust survivors $(\mathrm{N}=100)$ and a demographically comparable control group $(\mathrm{N}=44)$, adult offsprings of Holocaust survivors showed a significantly higher PTSD prevalence compared to the offsprings of the control subjects [79]. Analyses on a subset of the sample ( $\mathrm{N}=39$ offsprings of Holocaust survivors and $\mathrm{N}=15$ offsprings of the control group) further showed a significant negative correlation between severity of parental PTSD and offspring urinary cortisol, as well as a strong correlation between offspring PTSD symptom severity and their cortisol levels [80], suggesting a biological, transgenerational link between parental and filial PTSD symptomology $[80,81]$. In yet another follow-up study using a different sample, the same research group investigated the relationship between maternal cortisol levels (from 38 mothers directly exposed to the World Trade Center collapse) and cortisol levels from their one-year old infants. Lower cortisol levels were observed in both babies and their mothers who developed PTSD in response to September 11th compared with mothers who did not develop PTSD in response to the same event and their babies. Those findings might contain implications for the human telomere biology.

A meta-analysis by Costantini, Marasco, and Møller analyzed the effect of glucocorticoids on oxidative stress and noted that with an overall Perason's $r=.55$ the implications of glucocorticoids for oxidative stress were significant [82]. Haussmann and colleagues injected corticosterone into yolk of domestic chickens to test their hypothesis weather the exogenous corticosterone influences cellular ageing processes (i.e. oxidative stress and TL) during embryonic development [83]. For outcome variables they analyzed the relationship between reactive oxygen metabolites and total antioxidant capacity in two treatment groups (high and moderate corticosterone injection) and one control group. After injection and incubation, seven chickens per group remained for analyzes. Birds with elevated prenatal corticosterone showed more reactive oxygen metabolites after hatching and less total anti oxidative capacity compared to controls. This differences between the groups disappeared 40 minutes post-hatch, but all groups showed significantly more reactive oxygen metabolites and less total anti oxidative capacity. At the same time they found significantly shorter TL in blood plasma of birds with higher corticosterone injections. This study was most likely the first work that significantly demonstrated the prenatal effects of glucocorticoids on TL dynamics. But together with the findings on the influence of maternal stress on offspring TL [65,67], the new findings from animal models $[66,85]$ might suggest a link between the 4 factors cellular metabolism, inheritance, telomere biology and transgenerational consequences of PTSD and other stress related disorders.

Evidence, however, is not completely consistent and some studies question trans generational consequences of PTSD [84,85]. SagiSchwartz et al. [84] investigated a sample of 196 female subjects (48 Holocaust survivors and 50 controls, each had one daughter) to address trans generational effects form mothers to their daughters [84]. They found significant impacts of Holocaust in the first generation but not the second generation. In a meta-analytic approach from 2008 integrating 13 non-clinical samples with 1012 subjects the authors focused on a transmission of trauma to the third generation [85]. Like in their study on secondary traumatization, the group stated no effect of tertiary traumatization of Holocaust. Nevertheless, in both studies the authors focused on psychological outcomes only (e.g. attachment- style, cognitive worries, anxiety, general adjustment, aggression) but not on biological indicators like Yehuda et al. [80] in their study on cortisol levels of adult offspring. It is therefore of great importance to investigate whether TL is affected by trans generational effects of PTSD.

\section{Discussion}

TL shows high inter- and intra-individual variability, and tends to be crucially involved in the development of many physiological and psychological conditions, specifically when associated with stress. Besides the importance stress-related research, TL might be a useful biomarker in transgenerational psychobiological research and a potential target for a number of medical and bio psychosocial interventions.

Three findings underline the idea that TL is an optimal candidate for transgenerational PTSD research: a) TL is highly inherent and heritable, stressing a transgenerational approach b) high amounts of stress preceded the development of PTSD, which is also likely to influence TL maintenance as discussed above, and c) PTSD induces subsequent life-stress and arousal, which is why it is also likely to contribute to TL maintenance.

The biological framework for stress-TL associations has yet to be investigated, since there are currently two hypotheses, which might explain the association between TL erosion and psychological variables. The first hypothesis refers to an organism's elevated arousal during the experience of stress due to its inflammation [39]. More arousal leads to more bodily activity and metabolism that leads to increased cellular turnover. Elevated cellular turnover leads to more DNA replication and therefore faster TL erosion over time. The second hypothesis states that ROS (as molecular byproducts of metabolism) are responsible for DNA damage [34]. Besides other factors, psychological stress reduces anti oxidative activity. These two models are not mutually exclusive, and it is likely that both have a substantial part in the processes of TL erosion. More research is needed to complete the biological framework behind psychological stress and TL erosion.

It is likely that besides "normal" TL inheritance, TL erosion due to psychological stress might also be passed on to subsequent generations and thus leads to physiological and mental disadvantages in the filial generations. In other words, illness and diseases in subsequent generations could be due to direct multigenerational exposure to environmental factors, particularly to stress and trauma. However, it remains unclear whether transgenerational TL elongation due to higher PAC could compensate for such TL erosion. Clearly, further research is needed to understand the biological transgenerational effects of stress and trauma to prevent future adverse health outcomes in subsequent generations. So far, few studies have investigated the role of maternal prenatal stress-exposure in TL maintenance in their newborns. The studies consistently support the hypothesis that increased physiological activation (e.g. due to stress) or arousal can affect in utero telomere biology. However, it remains unclear whether antenatal stress (i.e., parental stress-exposure before conception) moderates germ-line transmission of TL. Though the significance and importance of PAC has been investigated in healthy subjects, it remains to be clarified whether the PAC-effect is fully or partially compensated in families with strong TL erosion due to high antenatal stress-exposure and whether maternal antenatal stress is transmitted to subsequent generations by the means of TL maintenance.

In conclusion, by deepening our understanding of the biological mechanisms underlying TL maintenance, and the relative importance 
of stress exposure for the trans generational development of stressrelated conditions and diseases via TL, telomere research may lead to the improvement of not only more appropriate disease treatments but also more suitable prevention approaches.

\section{Acknowledgement}

$A B$ reports an Ambizione Fellowship from the Swiss National Science Foundation.

\section{References}

1. McEwen BS, Stellar E (1993) Stress and the individual. Mechanisms leading to disease. Arch Intern Med 153: 2093-2101.

2. Juster RP, McEwen BS, Lupien SJ (2010) Allostatic load biomarkers of chronic stress and impact on health and cognition. Neurosci Biobehav Rev 35: 2-16.

3. Picard M, Juster RP, McEwen BS (2014) Mitochondrial allostatic load puts the 'gluc' back in glucocorticoids. Nat Rev Endocrinol 10: 303-310.

4. Shalev I (2012) Early life stress and telomere length: investigating the connection and possible mechanisms: a critical survey of the evidence base, research methodology and basic biology. Bioessays 34: 943-952.

5. Price LH, Kao HT, Burgers DE, Carpenter LL, Tyrka AR (2013) Telomeres and early-life stress: an overview. Biol Psychiatry 73: 15-23.

6. Shalev I, Entringer S, Wadhwa PD, Wolkowitz OM, Puterman E, et al. (2013) Stress and telomere biology: a lifespan perspective. Psychoneuroendocrinology 38: 1835-1842.

7. Juster RP, McEwen BS, Lupien SJ (2010) Allostatic load biomarkers of chronic stress and impact on health and cognition. Neurosci Biobehav Rev 35: 2-16.

8. Ressler KJ, Mercer KB, Bradley B, Jovanovic T, Mahan A, et al. (2011) Posttraumatic stress disorder is associated with PACAP and the PAC1 receptor. Nature 470: 492-497.

9. Epel ES, Blackburn EH, Lin J, Dhabhar FS, Adler NE, et al. (2004) Accelerated telomere shortening in response to life stress. Proc Natl Acad Sci U S A 101: $17312-17315$.

10. Kananen L, Surakka I, Pirkola S, Suvisaari J, Lönnqvist J, et al. (2010) Childhood adversities are associated with shorter telomere length at adult age both in individuals with an anxiety disorder and controls. PLoS One 5: e10826.

11. Kiecolt-Glaser JK, Gouin JP, Weng NP, Malarkey WB, Beversdorf DQ, et al. (2011) Childhood adversity heightens the impact of later-life caregiving stress on telomere length and inflammation. Psychosom Med 73: 16-22.

12. Malan S, Hemmings S, Kidd M, Martin L, Seedat S (2011) Investigation of telomere length and psychological stress in rape victims. Depress Anxiety 28 : 1081-1085.

13. Tyrka AR, Price LH, Kao HT, Porton B, Marsella SA, et al. (2010) Childhood maltreatment and telomere shortening: preliminary support for an effect of early stress on cellular aging. Biol Psychiatry 67: 531-534.

14. Blackburn EH, Gall JG (1978) A tandemly repeated sequence at the termin of the extrachromosomal ribosomal RNA genes in Tetrahymena. J Mol Biol 120: 33-53.

15. O'Sullivan RJ, Karlseder J (2010) Telomeres: protecting chromosomes against genome instability. Nat Rev Mol Cell Biol 11: 171-181.

16. Jain D, Cooper JP (2010) Telomeric strategies: means to an end. Annu Rev Genet 44: 243-269.

17. Njajou OT, Cawthon RM, Damcott CM, Wu SH, Ott S, et al. (2007) Telomere length is paternally inherited and is associated with parental lifespan. Proc Nat Acad Sci U S A 104: 12135-12139.

18. Slagboom PE, Droog S, Boomsma DI (1994) Genetic determination of telomere size in humans: a twin study of three age groups. Am J Hum Genet 55: 876 882.

19. Broer L, Codd V, Nyholt DR, Deelen J, Mangino M, et al. (2013) Meta-analysis of telomere length in 19,713 subjects reveals high heritability, stronger maternal inheritance and a paternal age effect. Eur J Hum Genet 21: 1163-1168.

20. Simon NM, Smoller JW, McNamara KL, Maser RS, Zalta AK, et al. (2006) Telomere shortening and mood disorders: preliminary support for a chronic stress model of accelerated aging. Biol Psychiatry 60: 432-435.
21. Vasa-Nicotera $M$, Brouilette $S$, Mangino $M$, Thompson JR, Braund $P$, et al (2005) Mapping of a major locus that determines telomere length in humans. Am J Hum Genet 76: 147-151.

22. Codd V, Nelson CP, Albrecht E, Mangino M, Deelen J, et al. (2013) Identification of seven loci affecting mean telomere length and their association with disease. Nat Genet 45: 422-427, 427e1-2.

23. Levy D, Neuhausen SL, Hunt SC, Kimura M, Hwang SJ, et al. (2010) Genomewide association identifies OBFC1 as a locus involved in human leukocyte telomere biology. Proc Natl Acad Sci U S A 107: 9293-9298.

24. Levy MZ, Allsopp RC, Futcher AB, Greider CW, Harley CB (1992) Telomere end-replication problem and cell aging. J Mol Biol 225: 951-960.

25. Harley CB (1991) Telomere loss: mitotic clock or genetic time bomb? Mutat Res 256: 271-282.

26. Cech TR, Thomas R, Lingner J (2008) end replication problem. Telomeres and Telomerase 791:20-34

27. Campisi J, d'Adda di Fagagna F (2007) Cellular senescence: when bad things happen to good cells. Nat Rev Mol Cell Biol 8: 729-740.

28. Vera E, Bernardes de Jesus B, Foronda M, Flores JM, Blasco MA (2012) The rate of increase of short telomeres predicts longevity in mammals. Cell Rep 2: 732-737.

29. Abdallah P, Luciano P, Runge KW, Lisby M, Géli V, et al. (2009) A two-step model for senescence triggered by a single critically short telomere. Nat Cell Biol 11: 988-993.

30. Greider CW, Blackburn EH (1989) A telomeric sequence in the RNA of Tetrahymena telomerase required for telomere repeat synthesis. Nature 337: 331-337.

31. Yu GL, Bradley JD, Attardi LD, Blackburn EH (1990) In vivo alteration of telomere sequences and senescence caused by mutated Tetrahymena telomerase RNAs. Nature 344: 126-132.

32. Gomez DE, Armando RG, Farina HG, Menna PL, Cerrudo CS, et al. (2012) Telomere structure and telomerase in health and disease (review). Int $\mathrm{J}$ Oncol 41: 1561-1569.

33. Smogorzewska A, de Lange T (2004) Regulation of telomerase by telomeric proteins. Annu Rev Biochem 73: 177-208.

34. von Zglinicki T (2002) Oxidative stress shortens telomeres. Trends Biochem Sci 27: 339-344.

35. Monaghan P, Metcalfe NB, Torres R (2009) Oxidative stress as a mediator of life history trade-offs: mechanisms, measurements and interpretation. Ecol Lett 12: $75-92$.

36. Fiskum G, Murphy AN, Beal MF (1999) Mitochondria in neurodegeneration acute ischemia and chronic neurodegenerative diseases. J Cereb Blood Flow Metab 19: 351-369.

37. Corral-Debrinski M, Horton T, Lott MT, Shoffner JM, Beal MF, et al. (1992) Mitochondrial DNA deletions in human brain: regional variability and increase with advanced age. Nat Genet 2: 324-329.

38. Gidron Y, Russ K, Tissarchondou H, Warner J (2006) The relation between psychological factors and DNA-damage: a critical review. Biol Psychol 72: 291304

39. Goronzy JJ, Fujii H, Weyand CM (2006) Telomeres, immune aging and autoimmunity. Exp Gerontol 41: 246-251.

40. Kimura M, Gazitt Y, Cao X, Zhao X, Lansdorp PM, et al. (2010) Synchrony of telomere length among hematopoietic cells. Exp Hematol 38: 854-859.

41. Youngren K, Jeanclos E, Aviv H, Kimura M, Stock J, et al. (1998) Synchrony in telomere length of the human fetus. Hum Genet 102: 640-643.

42. Nakamura K, Izumiyama-Shimomura N, Sawabe M, Arai T, Aoyagi $Y$, et al. (2002) Comparative analysis of telomere lengths and erosion with age in human epidermis and lingual epithelium. J Invest Dermatol 119: 1014-1019.

43. Okuda K, Bardeguez A, Gardner JP, Rodriguez P, Ganesh V, et al. (2002) Telomere length in the newborn. Pediatr Res 52: 377-381.

44. Thomas P, O' Callaghan NJ, Fenech M (2008) Telomere length in white blood cells, buccal cells and brain tissue and its variation with ageing and Alzheimer's disease. Mech Ageing Dev 129: 183-190. 
45. Friedrich U, Griese E, Schwab M, Fritz P, Thon K, et al. (2000) Telomere length in different tissues of elderly patients. Mech Ageing Dev 119: 89-99.

46. Willeit P, Willeit J, Kloss-Brandstätter A, Kronenberg F, Kiechl S (2011) Fifteenyear follow-up of association between telomere length and incident cancer and cancer mortality. JAMA 306: 42-44.

47. Willeit P, Willeit J, Mayr A, Weger S, Oberhollenzer F, et al. (2010) Telomere length and risk of incident cancer and cancer mortality. JAMA 304: 69-75.

48. O'Donovan A, Pantell MS, Puterman E, Dhabhar FS, Blackburn EH, et al. (2011) Cumulative inflammatory load is associated with short leukocyte telomere length in the Health, Aging and Body Composition Study. PLoS One 6: e19687.

49. Epel ES, Merkin SS, Cawthon R, Blackburn EH, Adler NE, et al. (2008) The rate of leukocyte telomere shortening predicts mortality from cardiovascular disease in elderly men. Aging (Albany NY) 1: 81-88.

50. Fitzpatrick AL, Kronmal RA, Gardner JP, Psaty BM, Jenny NS, et al. (2007) Leukocyte telomere length and cardiovascular disease in the cardiovascular health study. Am J Epidemiol 165: 14-21.

51. Herborn KA, Heidinger BJ, Boner W, Noguera JC, Adam A, Daunt F, Monaghan $P(2014)$ Stress exposure in early post-natal life reduces telomere length?: an experimental demonstration in a long-lived seabird Stress exposure in early post-natal life reduces telomere length?: an experimental demonstration in a long-lived seabird Author for co. Proc R Soc B 281:e20133151

52. Kotrschal A, Ilmonen P, Penn DJ (2007) Stress impacts telomere dynamics. Biol Lett 3: 128-130.

53. Shalev I, Moffitt TE, Sugden K, Williams B, Houts RM, et al. (2013) Exposure to violence during childhood is associated with telomere erosion from 5 to 10 years of age: a longitudinal study. Mol Psychiatry 18: 576-581.

54. Drury SS, Theall K, Gleason MM, Smyke AT, De Vivo I, et al. (2012) Telomere length and early severe social deprivation: linking early adversity and cellular aging. Mol Psychiatry 17: 719-727.

55. Drury SS, Mabile E2, Brett ZH3, Esteves K3, Jones E3, et al. (2014) The association of telomere length with family violence and disruption. Pediatrics 134: e128-137.

56. Savolainen K, Räikkönen K, Kananen L, Kajantie E, Hovatta I, et al. (2012) History of mental disorders and leukocyte telomere length in late adulthood: the Helsinki Birth Cohort Study (HBCS). J Psychiatr Res 46: 1346-1353.

57. Surtees PG, Wainwright NW, Pooley KA, Luben RN, Khaw KT, et al. (2011) Life stress, emotional health, and mean telomere length in the European Prospective Investigation into Cancer (EPIC)-Norfolk population study. J Gerontol A Biol Sci Med Sci 66: 1152-1162.

58. Ladwig KH, Brockhaus AC, Baumert J, Lukaschek K, Emeny RT, et al. (2013) Posttraumatic stress disorder and not depression is associated with shorter leukocyte telomere length: findings from 3,000 participants in the populationbased KORA F4 study. PLoS One 8: e64762.

59. Zhang L, Hu XZ, Benedek DM, Fullerton CS, Forsten RD2, et al. (2014) The interaction between stressful life events and leukocyte telomere length is associated with PTSD. Mol Psychiatry 19: 856-857.

60. Shalev I, Moffitt TE, Braithwaite AW, Danese A, Fleming NI, et al. (2014) Internalizing disorders and leukocyte telomere erosion: a prospective study of depression, generalized anxiety disorder and post-traumatic stress disorder. Mol Psychiatry .

61. Bale TL, Baram TZ, Brown AS, Goldstein JM, Insel TR, et al. (2010) Early life programming and neurodevelopmental disorders. Biol Psychiatry 68: 314-319.

62. Barker DJ (2007) The origins of the developmental origins theory. J Intern Med 261: 412-417.

63. Godfrey KM, Gluckman PD, Hanson MA (2010) Developmental origins of metabolic disease: life course and intergenerational perspectives. Trends Endocrinol Metab 21: 199-205.

64. Jirtle RL, Skinner MK (2007) Environmental epigenomics and disease susceptibility. Nat Rev Genet 8: 253-262.

65. Gapp K, Jawaid A, Sarkies P, Bohacek J, Pelczar P, et al. (2014) Implication of sperm RNAs in transgenerational inheritance of the effects of early trauma in mice. Nat Neurosci 17: 667-669.

66. Entringer S, Epel ES, Kumsta R, Lin J, Hellhammer DH, et al. (2011) Stress exposure in intrauterine life is associated with shorter telomere length in young adulthood. Proc Natl Acad Sci U S A 108: E513-518.

67. Entringer S, Epel ES, Lin J, Buss C, Shahbaba B, et al. (2013) Maternal psychosocial stress during pregnancy is associated with newborn leukocyte telomere length. Am J Obstet Gynecol 208: 134.

68. Allsopp RC, Vaziri H, Patterson C, Goldstein S, Younglai EV, et al. (1992) Telomere length predicts replicative capacity of human fibroblasts. Proc Natl Acad Sci U S A 89: 10114-10118.

69. Stoop H, Honecker F, Cools M, de Krijger R, Bokemeyer C, Looijenga LHJ (2005) Differentiation and development of human female germ cells during prenatal gonadogenesis: an immunohistochemical study. Hum Reprod 20:1466-76

70. Kimura M, Cherkas LF, Kato BS, Demissie S, Hjelmborg JB, et al. (2008) Offspring's leukocyte telomere length, paternal age, and telomere elongation in sperm. PLoS Genet 4: e37.

71. De Meyer T, Rietzschel ER, De Buyzere ML, De Bacquer D, Van Criekinge W, et al. (2007) Paternal age at birth is an important determinant of offspring telomere length. Hum Mol Genet 16: 3097-3102.

72. Unryn BM, Cook LS, Riabowol KT (2005) Paternal age is positively linked to telomere length of children. Aging Cell 4: 97-101.

73. Kimura M, Hjelmborg JV, Gardner JP, Bathum L, Brimacombe M, et al. (2008) Telomere length and mortality: a study of leukocytes in elderly Danish twins. Am J Epidemiol 167: 799-806.

74. Arbeev KG, Hunt SC, Kimura M, Aviv A, Yashin Al (2011) Leukocyte telomere length, breast cancer risk in the offspring: the relations with father's age at birth. Mech Ageing Dev 132: 149-153.

75. Eisenberg DT, Kuzawa CW (2013) Commentary: The evolutionary biology of the paternal age effect on telomere length. Int J Epidemiol 42: 462-465.

76. Afifi TO, Asmundson GJ, Taylor S, Jang KL (2010) The role of genes and environment on trauma exposure and posttraumatic stress disorder symptoms: a review of twin studies. Clin Psychol Rev 30: 101-112.

77. Stein MB, Jang KL, Taylor S, Vernon PA, Livesley WJ (2002) Genetic and environmental influences on trauma exposure and posttraumatic stress disorder symptoms: a twin study. Am J Psychiatry 159: 1675-1681.

78. True WR, Rice J, Eisen SA, Heath AC, Goldberg J, et al. (1993) A twin study of genetic and environmental contributions to liability for posttraumatic stress symptoms. Arch Gen Psychiatry 50: 257-264.

79. Yehuda R, Schmeidler J, Wainberg M, Binder-Brynes K, Duvdevani T (1998) Vulnerability to posttraumatic stress disorder in adult offspring of Holocaust survivors. Am J Psychiatry 155: 1163-1171.

80. Yehuda R, Halligan SL, Bierer LM (2002) Cortisol levels in adult offspring of Holocaust survivors: relation to PTSD symptom severity in the parent and child. Psychoneuroendocrinology 27: 171-180.

81. Yehuda R (2002) Post-traumatic stress disorder. N Engl J Med 346: 108-114.

82. Costantini D, Marasco V, Møller AP (2011) A meta-analysis of glucocorticoids as modulators of oxidative stress in vertebrates. J Comp Physiol B 181: 447456.

83. Haussmann MF, Longenecker AS, Marchetto NM, Juliano SA, Bowden RM (2012) Embryonic exposure to corticosterone modifies the juvenile stress response, oxidative stress and telomere length. Proc Biol Sci 279: 1447-1456.

84. Sagi-Schwartz A, Van IJzendoorn MH, Grossmann KE, Joels T, Grossmann $\mathrm{K}$, et al. (2003) Attachment and traumatic stress in female holocaust child survivors and their daughters. Am J Psychiatry 160: 1086-1092.

85. Sagi-Schwartz A, van IJzendoorn MH, Bakermans-Kranenburg MJ (2008) Does intergenerational transmission of trauma skip a generation? No metaanalytic evidence for tertiary traumatization with third generation of Holocaust survivors. Attach Hum Dev 10: 105-121. 